\title{
Chest Wall Resection and Reconstruction as a Substitute to Treat Malignant Tumours in Chinese Patients
}

\author{
Y Yu, S Ding, Y Liang, Y Zheng, W Li, L Yang, X Zheng, J Jiang
}

\begin{abstract}
Objectives: Chest wall cancers are a mixed group of lesions that offer an exciting diagnostic and therapeutic challenge for surgeons. The present study is an attempt to evaluate the pathology, treatment methodologies, role of surgical resection and reconstruction, and consequences of patients with these tumours.

Methods: All the patients with malignant primary chest wall cancers treated at our institution between February 2007 and July 2013, were included in this study. Fifteen cases were identified with tumours. Seven of them were malignant small round cell tumour (MSRCT), six were rhabdomyosarcoma (RMS) and the remaining two were other tumours. Five patients underwent initial biopsy, followed by chemotherapy $(n=4)$ and radiotherapy $(n=1)$.

Results: Three of these five survived to undertake late chest wall resections. Six of the nine resected patients required en bloc resection of neighbouring muscles or organs; three required complex chest wall reconstruction. At the end of the study, we found that eight out of 15 patients (53\%) have survived (six years of follow-up), all with no evidence of disease; the other seven patients died of progressive disease. Two patients with tumour categories other than MSRCT or RMS, metastatic or not, at diagnosis, are alive with no indication of disease. There were no local recurrences.

Conclusions: Surgical resection, with en bloc removal of involved structures and chest wall reconstruction, provides outstanding survival improvement in malignant chest wall tumours.
\end{abstract}

Keywords: Chemotherapy, malignant small round cell tumour (MSRCT), rhabdomyosarcoma, radiotherapy, surgical resection

WIMJ Open 2015; 2 (2): 66

\section{INTRODUCTION}

Malignant chest wall tumours are categorized into eight important diagnostic categories: muscular, vascular, fibrous and fibrohistiocytic, peripheral nerve, osseous and cartilaginous, adipose, haematologic, and cutaneous. However, malignant tumours such as Ewing's sarcoma and synovial sarcoma arise in the chest wall but do not fit well in any of these categories (1). The Ewing sarcoma group of tumours including Askin tumour of the chest wall, and primitive neuroectodermal tumour is a gamut of small round-cell tumours. Moreover, these tumours are the third most common malignant chest wall tumours overall and are common mostly in the paediatric and young adult population.

From: Department of Thoracic Surgery, General Hospital of Chengdu Military Region of People Liberation's Army, Chengdu Rong Road, No. 270, Jinniu District, Chengdu 610083, China.

Correspondence: Dr J Jiang, Department of Thoracic Surgery, General Hospital of Chengdu Military Region of People Liberation's Army, Chengdu Rong Road, No. 270, Jinniu District, Chengdu 610083, China. Fax: 0086-028-65580373, e-mail: jianqingjiang777@gmail.com
The Ewing sarcoma family is a destructive tumour family with high reappearance rates and has high possibility of metastases (2).

Chest wall tumours can fluctuate from benign to malignant and may arise from any soft tissue or bony structure. More than $50 \%$ of chest wall tumours are malignant, typically comprising direct invasion or metastases from adjacent thoracic tumours (3). Rhabdomyosarcomas in the chest wall typically manifest as promptly growing masses and may cause pain and other indications due to nerve compression. Bone invasion by a primary tumour occurs in more than $20 \%$ of patients. Rhabdomyosarcoma has several histologic subtypes such as embryonal, alveolar and pleomorphic (4). In all rhabdomyosarcoma subtypes, as in other soft-tissue tumours, computed tomography (CT) and magnetic resonance imaging (MRI) permit optimal estimation of tumour magnitude and nodular involvement. Other key investigative tools are biopsies. These are used for the diagnosis of lesions extending from simple periapical lesions to malignancies. It is frequently the only way to diagnose oral lesions and diseases and, as with most procedures, there is often more than one 
technique of undertaking the surgery successfully (5). Tumours not thought of being a primary neoplasm should ideally be diagnosed by excisional rather than by incisional biopsy. In case the lesion is too large, an incisional biopsy can be executed.

Moreover, radiotherapy is an important and economical therapeutic treatment for malignancy (6). Around 50\% of cancer patients are treated by radiotherapy and it is a key component of treatment for around $40 \%$ of those cured (7). In case of tumours that are metastatic at diagnosis, partial surgical resection is sometimes directed for well-demarcated lesions, otherwise, as in most cases, management is belligerent chemotherapy and radiotherapy. The challenges of diagnosis, complete resection and reconstruction have posed trouble for surgeons making an effort to minimize perioperative morbidity in the past, but developments in all of these areas have significantly improved long-term survival and declined recurrence rates (8). This report describes our experience with patients having malignant chest wall tumours and the results obtained from their treatment with various combinations of chemotherapeutic protocols, surgical resection and radiotherapy.

\section{SUBJECTS AND METHODS}

This study was carried out on 15 patients with malignant chest wall tumours admitted in the Department of Thoracic Surgery, General Hospital of Chengdu Military Region of PLA, Chengdu, China, between 2007 and 2013. Their ages ranged from four to eight years (children), 17 to 24 years (young) and 41 to 50 years (old age). Thirteen patients were males and two were females. In this investigation, only primary tumours of the ribs, scapula, clavicle, sternum and their associated soft tissues were included (Table 1) and the rest were excluded ie tumours arising primarily from within the mediastinum with secondary involvement of the chest wall, as well as tumours of the vertebrae.
For every patient, the following investigations were done.

\section{CT scan/MRI}

We can rule out chest wall tumours to an extent and can even find out the progression and staging of the tumours. For all patients with a mass, a CT scan or MRI of the chest was done in order to know the position of the lesion; for tissue diagnosis, fine/core needle aspiration or incisional biopsy was attempted.

\section{Computed axial tomography (CAT)}

For patients with supposed metastases, CAT scans were used. The ionizing radiations in the form of X-rays used in CT scans are energetic enough to directly or indirectly damage DNA. Table 2 lists the CAT scanning dosages.

Table 2: Computed axial tomography (CAT) scanning dosage

\begin{tabular}{lcc}
\hline Examination & $\begin{array}{c}\text { Typical effective dose } \\
(\mathbf{m S v})\end{array}$ & $\begin{array}{c}\text { Typically absorbed dose } \\
(\mathbf{m G y})\end{array}$ \\
\hline Chest X-ray & 0.02 & $0.01-0.015$ \\
Chest CT & $5-7$ & 13 \\
\hline
\end{tabular}

\section{Biopsy}

Five out of fifteen patients underwent biopsy. Of these, four were excisional biopsy where the entire lump was removed; the remaining one underwent incisional/core biopsy.

\section{Chemotherapy}

Chemotherapy was administered as per standard protocol. All the seven patients with malignant small round cell tumour (MSRCT) received vincristine, actinomycin-D or doxorubicin and cyclophosphamide. Along with these, four patients had received ifosphamide and etoposide. One patient had received ifosphamide and etoposide, with

Table 1: The age group, diagnosis, location and metastasis of patients

\begin{tabular}{lllll}
\hline Patient no. & $\begin{array}{c}\text { Age (year) } \\
\text { /gender }\end{array}$ & Diagnosis & Primary site & Metastasis \\
\hline 1 & $17 / \mathrm{M}$ & MSRCT & Chest wall & bones \\
2 & $4 / \mathrm{M}$ & MSRCT & $5^{\text {th }}$ rib & bones \\
3 & $19 / \mathrm{M}$ & MSRCT & $9^{\text {th }}$ rib & bones \\
4 & $44 / \mathrm{F}$ & MSRCT & Chest wall & none \\
5 & $41 / \mathrm{M}$ & MSRCT & $3^{\text {th }}$ rib & pulm \\
6 & $21 / \mathrm{M}$ & MSRCT & $4^{\text {th }}$ rib & bones \\
7 & $17 / \mathrm{M}$ & MSRCT & $10^{\text {th }}$ rib & none \\
8 & $23 / \mathrm{M}$ & Alv rhabdomyosarcoma & Chest wall & bones \\
9 & $6 / \mathrm{M}$ & Alv rhabdomyosarcoma & Clavicle & bones \\
10 & $24 / \mathrm{M}$ & Alv rhabdomyosarcoma & Clavicle & none \\
11 & $8 / \mathrm{M}$ & Embr rhabdomyosarcoma & $5^{\text {th }}$ rib & none \\
12 & $50 / \mathrm{M}$ & Embr rhabdomyosarcoma & Chest wall & none \\
13 & $8 / \mathrm{M}$ & Embr rhabdomyosarcoma & $4^{\text {th }}$ rib & none \\
14 & $18 / \mathrm{F}$ & Osteosarcoma & Scapula & none \\
15 & $19 / \mathrm{M}$ & Synovial sarcoma & Chest wall & none \\
\hline
\end{tabular}

MSRCT: malignant small round cell tumour; Alv: alveolar; Embr: embryonal 
cisplatin added later. Two of three patients with alveolar rhabdomyosarcoma (RMS) received vincristine, doxorubicin and cyclophosphamide (VDC) along with ifosphamide, etoposide and cisplatin; the remaining one patient received vincristine and actinomycin-D (VA) along with ifosphamide and etoposide. Two out of three patients with embryonal RMS received vincristine, actinomycin-D and cyclophosphamide (VAC)/VDC along with ifosphamide and etoposide; the remaining one patient received VAC. Patients with osteosarcoma received ifosphamide and high-dose methotrexate, whereas patients with synovial sarcoma received VAC along with ifosphamide and etoposide.

\section{Surgical resection}

In addition to the above, surgical resection was performed on ten out of fifteen patients. Five out of seven MSRCT patients and four out of six RMS patients underwent resection. One patient with osteosarcoma underwent surgical resection.

\section{Radiotherapy}

Four out of fifteen patients received radiotherapy. Two of these underwent surgical resection (one was treated before resection and one after resection). The total dosage of radiation per patient ranged from 2400 to $8940 \mathrm{cGy}$. Patient summaries of individual cases are shown in Table 3.

\section{RESULTS}

At the end of the study, we observed two patients with tumours other than MSRCT or RMS to be continuously disease free, 4.5 to six years after diagnosis.

\section{MSRCT}

Three patients out of seven with MSRCT showed no evidence of disease with a follow-up of six years. Despite intensive regimens of chemotherapy or radiotherapy, four patients died during follow-up of one to six years, because of disease progression. The survival rate of MSRCT was thus $42.8 \%$.

\section{RMS patients}

Three out of six patients with RMS showed no evidence of disease during a follow-up of six years. The other three patients died of disease progression despite intensive regimens of chemotherapy or radiotherapy after follow-up of 1.2 to six years. The survival rate of RMS patients was found to be $50 \%$. The estimated survival was higher for patients with RMS when compared to MSRCT (Table 4, Figure).

Most of the patients experienced complications after chemotherapy. Three patients were admitted for anaemia and two patients for alopecia and thrombocytopenia. Complications also occurred in five out of nine patients after surgical resection. From two of these five patients, three ribs were removed and they suffered from pleural effusion and lung disease, whereas the other three patients suffered from scoliosis and chest wall deformity. Four out of nine patients underwent surgical resection with a survival rate of $44 \%$. Radiotherapy was implemented in four patients and their survival rate was shown with follow-up of six years.

Table 3: Treatments and surgical procedures

\begin{tabular}{|c|c|c|c|}
\hline $\begin{array}{l}\text { Patient } \\
\text { no. }\end{array}$ & Chemotherapy* & $\begin{array}{l}\text { Radiotherapy } \\
\text { (cGy) }\end{array}$ & Surgical procedure \\
\hline 1 & D-VAC-IE & 4700 lung & Biopsy \\
\hline 2 & D-VAC-IE-Cp & None & $\begin{array}{l}\text { En bloc resection of ribs 3-7; Marlex mesh, } \\
\text { latissimus dorsi muscle flap }\end{array}$ \\
\hline 3 & D-VAC-IE & None & En bloc resection of rib 9 \\
\hline 4 & $\mathrm{D}-\mathrm{VC}$ & None & Biopsy \\
\hline 5 & $\mathrm{D}-\mathrm{VC}$ & None & En bloc resection of sulcus tumour \\
\hline 6 & VAC-IE & 2400 chest & En bloc resection of rib 9 and intercostal muscle \\
\hline 7 & D-VC-IE & None & En bloc resection of rib 10 and intercostal muscle \\
\hline 8 & D-VC-IE-Cp & None & En bloc resection of posterior chest wall \\
\hline 9 & VA-IE & None & Biopsy \\
\hline 10 & D-VC-IE-Cp & None & Biopsy \\
\hline 11 & D-VAC-IE & 3590 lung & En bloc resection of rib 5 \\
\hline 12 & D-VAC-IE & None & $\begin{array}{l}\text { En bloc resection of entire ribs } 2,3,5, \mathrm{~T} 1-\mathrm{T} 6 \\
\text { spinous processes }\end{array}$ \\
\hline 13 & VAC & None & $\begin{array}{l}\text { En bloc resection of lateral chest wall; Marlex } \\
\text { mesh reconstruction }\end{array}$ \\
\hline 14 & I-HDM & 8940 lung & $\begin{array}{l}\text { Forequarter amputation of left upper extremity and } \\
\text { shoulder, latissimus dorsi muscle flaps }\end{array}$ \\
\hline 15 & VAC-IE & None & Biopsy \\
\hline
\end{tabular}

*All drugs received during treatment course.

D: doxorubicin; V: vincristine; A: actinomycin-D; C: cyclophosphamide; I: ifosphamide; E: etoposide; Cp: cisplatin; HDM: high-dose methotrexate 
Table 4: Patients and their outcome

\begin{tabular}{lcc}
\hline Outcome & $\begin{array}{c}\text { Follow-up } \\
\text { intervals (years) }\end{array}$ & $\begin{array}{c}\text { Patient } \\
\text { no. }\end{array}$ \\
\hline NED & 1 & 1 \\
DOD & 4.4 & 2 \\
DOD & 1.2 & 3 \\
DOD & 1.8 & 4 \\
NED & 3.9 & 5 \\
NED & 4 & 6 \\
DOD & 3 & 7 \\
NED & 1.2 & 8 \\
DOD & 2 & 9 \\
NED & 5 & 10 \\
NED & 6 & 11 \\
DOD & 2.1 & 12 \\
DOD & 3.6 & 13 \\
NED & 4.5 & 14 \\
NED & 6 & 15 \\
\hline
\end{tabular}

NED: no evidence of disease; DOD: died of disease

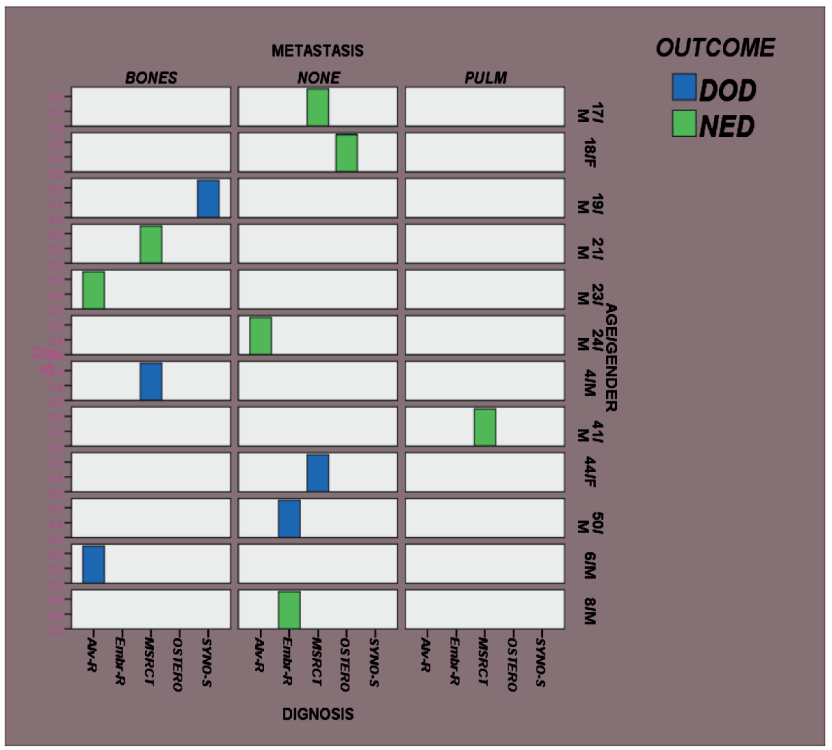

Figure: Graphical representation of pathology, age group, metastasis and outcome of patients.

DOD: died of disease; NED: no evidence of disease; Alv-R: alveolar rhabdomyosarcoma, Embr-R: embryonal rhabdomyosarcoma; MSRCT: malignant small round cell tumour; OSTERO: osteosarcoma; SYNO-S: synovial sarcoma

\section{DISCUSSION}

Malignant small round cell tumours including Ewing's sarcoma, primitive neuroectodermal tumour (PNET) and Askin's tumour are the most common primary chest wall malignancies in children and adults (9). Rhabdomyosarcomas are the most common soft tissue sarcomas in children. Rhabdomyosarcomas have alveolar and embryonal subtypes. Malignant small round cell tumours arise in the chest wall up to $6.5 \%$ in children, whereas it is up to $5 \%$ with RMS $(10,11)$. In our study, the most frequent site was single rib $(n=7 ; 46.7 \%)$, followed by chest wall $(n=5 ; 33.3 \%)$, clavicle $(\mathrm{n}=2 ; 13.3 \%)$ and the scapula $(\mathrm{n}=1 ; 6.7 \%)$. Previous studies have shown that the most common site of primary tumour occurrence in the adult population was the rib $(12,13)$.

Treatment of MSRCTs and RMS has been directed toward control of both local disease and distant spread. Local control of MSRCTs has been achieved with radiotherapy, depending on the location, size and volume of the primary tumour (14). In our study, four out of 15 patients received radiotherapy. All the patients survived, with a follow-up interval of six years.

Chemotherapy (vincristine, doxorubicin and cyclophosphamide along with etoposide and ifosfamide) showed improved survival rate (15). Patients with primary metastatic Ewing's tumour receiving myeloblative mega therapy and stem cell rescue after conventional treatment showed improved outcome, as reported by Paulussen et al (16). In our study, bone is the most frequent site of metastasis in MSRCT. Five of seven MSRCT patients presented with metastases. Three of these five patients lived and the remaining two patients died from the effect of the disease.

Surgical management and reconstruction of widespread chest wall malignancies irrespective of size was done by Ramming et al (17). The ribs below and above the tumour, adjacent muscles and pleura should be cut out surgically when the treatment is of a primary tumour. For the tumours at the clavicle, whole removal of involved and neighbouring structures is to be done (13).

Several materials and techniques have been employed to reconstruct chest wall defects which include fascia lata, omental transplants, contralateral rib grafts, assorted muscle flaps and prosthetic materials. The most commonly used materials are synthetic mesh fabrics like Gortex, Prolene, Marlex, Teflon and Dexon. Griselda et al reported that Gortex is recommended for chest wall resections and reconstructions in childhood and few patients showed longterm complications such as scoliosis and chest wall deformity which are related to surgical resection and surgical reconstruction (18). Selected patients with multimodal adjuvant therapy showed disease-free survival improved from $50 \%$ to $66 \%$ (11). For poor-risk peripheral primitive neuro-ectodermal tumours, including Ewing's sarcoma in children and young adults, very-high-dose-short-term chemotherapy consisting of four courses of the combined regimen of vincristine, adriamycin and cyclophosphamide have been reported (19). Our study comprised three courses of chemotherapy, after which a chest wall resection was performed to surgically remove the tumour. After resection, an additional course of vincristine, adriamycin and cyclophosphamide was then given. This was then followed by three courses of chemotherapy with ifosfamide and etoposide.

We have shown a favourable survival rate in patients with chest wall tumours. Regarding radiotherapy, it is difficult to make any definite conclusions based on our data with 
a small number of patients. The key to successful treatment remains on local control of disease, because the failure to accomplish this results in the reappearance of disease and the feasible development of distant metastases. Surgery is executed with removal of all involved structures; chemotherapy is then administered in a course similar to that which preceded surgery. This is followed by adjuvant radiotherapy to eliminate remaining tumour and abolish microscopic lymphatic and haematogenous deposits of cancer spread.

This is one of the institutions describing the treatment of chest wall tumours. The best preoperative design in pointing toward tumour characterization and its extent is conducted by CT or MRI techniques. On the basis of our experience, we conclude that to plan a correct surgical procedure, preoperative staging using $\mathrm{CT}$ is useful to detect abnormalities. Chest wall tumours are a motivating, analytic and therapeutic challenge for reconstructive surgeons. Careful preoperative evaluation of the patient, radiographic imaging and histopathology are required. For several patients, a multidimensional approach is necessary for optimal outcome as it relates to cancer mortality and long-standing function. For patients with malignant and metastatic tumours of the chest wall, excellent outcomes can be obtained by complete surgical resection and appropriate reconstruction. Despite improvements in survival, obtaining local control is challenging and often accompanied by morbidity. The main task should be on recognizing tumours easily and improving radiotherapy techniques.

\section{REFERENCES}

1. Ukihide T, Gregory WG, Masahiko K, Tadashi H, Ryohei Y, Ryosuke T et al. Chest wall tumors: radiologic findings and pathologic correlation. Radiographics 2003; 23: 1491-508.

2. Lee WS, Kim YH, Chee HK. Multimodal treatment of primary extraskeletal Ewing's sarcoma of the chest wall: report of 2 cases. Cancer Res Treat 2009; 41: 108-112.

3. Park BJ, Flores RM, Shields TW, Locicero J, Reed CE, Feins RH, eds. General thoracic surgery. Philadelphia, PA: Lippincott; 2009: 669-78.

4. Kransdorf MJ. Malignant soft-tissue tumors in a large referral population: distribution of diagnoses by age, sex, and location. AJR Am J Roentgenol 1995; 164: 129-34.

5. Oliver RJ, Sloan P, Pemberton MN. Oral biopsies, methods and applications. Br Dent J 2004; 196: 329-33.

6. Bentzen SM, Heeren G, Cottier B, Slotman B, Glimelius B, Lievens Y et al. Towards evidence-based guidelines for radiotherapy infrastructure and staffing needs in Europe: the ESTRO QUARTS project.
Radiother Oncol 2005; 75: 355-65.

7. Price P, Sikora K. Treatment of cancer. $5^{\text {th }}$ ed. London: Arnold Hodder; 2008.

8. Shah AA, D’Amico TA. Primary chest wall tumors. J Am Coll Surg 2010; 210: 360-6.

9. Malangoni M, Ofstein LC, Grosfeld JL, Weber TR, Eigen H, Baehner RL. Survival and pulmonary function following chest wall resection and reconstruction in children. J Pediatr Surg 1980; 15: 906-12.

10. Shamberger RC, Grier HE. Chest wall tumors in infants and children. Sem Pediatr Surg 1994; 3: 267-76.

11. Saenz NC, Ghavimi F, Gerald W. Chest wall rhabdomyosarcoma. Cancer 1997; 80: 1513-17.

12. Burt M, Karpeh M, Ukoha O, Bains MS, Martini N, McCormack PM et al. Medical tumors of the chest wall. J Thorac Cardiovasc Surg 1993; 105: 89-96.

13. Sabanathan S, Salama FD, Morgan WE, Harvey JA. Primary chest wall tumors. Ann Thorac Surg 1985; 39: 4-15.

14. Shamberger RC, Grier HE, Weinstein HJ, Perez-Atayde AR, Tarbell NJ. Chest wall tumors in infancy and childhood. Cancer 1989; 63: 774-85.

15. Grier H, Krailo M, Link M, Tanbell N, Fryer C, Pritchard D et al. Improved outcome in non-metastatic Ewing's sarcoma (EWS) and PNET of bone with the addition of ifosfamide (I) and etoposide (E) to vincristine (V), Adriamycin (Ad), cyclophosphamide (C) and actinomycin (A): a Children's Cancer Group (CCG) and Pediatric Oncology Group (POG) report [Abstract]. Proc Am Soc Clin Oncol 1994; 13: 421.

16. Paulussen M, Ahrens S, Burdach S, Craft A, Dockhorn-Dworniczak B, Dunst J et al. Primary metastatic (stage IV) Ewing tumor: survival analysis of 171 patients from the EICESS studies. Ann Oncol 1998; 9: 275-81.

17. Ramming KP, Holmes EC, Zarem HA, Lesavoy MA, Morton DL. Surgical management and reconstruction of extensive chest wall malignancies. Am J Surg 1982; 144: 146-52.

18. Griselda JL, Rescorla FJ, West KW, Vane DW, DeRosa GP, Provisor AJ et al. Chest wall resection and reconstruction for malignant conditions in childhood. J Pediatr Surg 1988; 231: 667-73.

19. Kushner BH, Meyers PA, Gerald WL, Healey JH, LaQuaglia MP, Boland P et al. Very-high-dose-short-term chemotherapy for poorrisk peripheral primitive neuroectodermal tumors, including Ewing's sarcoma, in children and young adults. J Clin Oncol 1995; 13: 2796804.

Received 06 Oct 2014

Accepted 15 Oct 2014

Published 28 May 2015

Online: http://www.mona.uwi.edu/wimjopen/article/1613

(C) Yu et al 2015.

This is an open access article made freely available under Creative Commons Attribution 4.0 International (CC BY 4.0). Users are free to share, copy and adapt this work as long as the copyright holder (author) is appropriately and correctly credited. See http://creativecommons.org/ licences/by/4.0/deed.en_us for more information. 